\title{
Decani Bistrica River Basin Waters
}

\author{
Sali Fazliu ${ }^{1}$ and Enkelejda Gjinali ${ }^{2}$
}

1. Department of Water Recourses Management, University of Pristine for Civil Engineering, Pristine 10000, Republic of Kosova

2. Department of Environmental Engineering, Polytechnic University of Tirana, Tirana 1000, Albania

\begin{abstract}
The catchment in Republic of Kosova can be divided in basins of the rivers as: basin of White Drino in village Radavc, Peja municipality; basin of river Iber, Mitrovica municipality; basin of river Morava of Binca, Gjilani municipality and basin of river Lepenci in Kacanik municipality. The watershed subject to this paper belongs to the basin of White Drino which belongs to the Adriatic sea catchment. This river occupies nearly $6.13 \%$ of the catchment of "White Drino" and has several positive features which make it more interesting for the study such as a considerable amount of annual rainfall and a distinct topography providing strong currents. The study comprises of a detailed analysis of the quantity of water which can be accumulated and used for water supply, irrigation for agricultural, production of electric hydropower and recreation.
\end{abstract}

Key words: Catchment, river basin, stream, rainfall, utilizations of water resources.

\section{Introduction}

The usage of river water of Bistrica of Decani is based on the basis of the analysis for water resources management according to Eq. (1):

$$
\mathrm{V}=(\mathrm{L}, \mathrm{K}, \mathrm{Q})
$$

where $\mathrm{L}$ means spatial position of the water source $(\mathrm{km})$; Q means amount of water $\left(\mathrm{m}^{3} / \mathrm{s}\right)$; K means water quality.

The analysis is made on such a way that all concerned parties for water meet their demands [1].

In Fig. 1, a general map of all Kosovo rivers is presented. The river "Lumebardhi" is one of the rivers of Kosovo, which has a fairly stable flow. The authors' opinion is that the average flow of is quite high and has a long-time duration as Eq. (2):

$$
Q_{a v}=4.72 \mathrm{~m}^{3} / \mathrm{s}
$$

Other characteristic values are in different time intervals and suitable for use as Eqs. (3) and (4) [1]:

$$
\begin{gathered}
Q_{\min }=0.960 \mathrm{~m}^{3} / \mathrm{s} \\
\text { And } Q_{\max }=152.2 \mathrm{~m}^{3} / \mathrm{s}
\end{gathered}
$$

River Lumebardhi of Decani has nearly $6.13 \%$ from the surface of catchment of river White Drino. The

Corresponding author: Sali Fazliu, master of technical sciences, main research fields: environmental engineering and managing water resources. average of rainfall perennial is $H_{\text {sh.v.mes }}=$ $1,090 \mathrm{~mm}$ [2]. The "White Drino" stream is around $350.00 \mathrm{nmm}$, while the highest quota of basin is nearly $2,400.00 \mathrm{nmm}$.

Water demands continue to increase. Meeting the interested need for pure water is becoming more and more difficult as Kosovo's water resources are limited. Every conversation, may that be in politics, economy, culture, health or other, begins with the word water. Is there water? What is the amount of water? Will there be non-stop drinking water, water for industry, for agriculture, etc.? This is the conversation in any political presentation when there are tendencies to govern a country.

In all partisan presentation or when a political conversation takes place, it is stated or promised that the drinking water system will be constructed or improved, or the system of removing sewage or constructing facilities to protection from floods, and there will be water for drinking, irrigation, etc..

In any economy planning, the goal of having a sufficient amount of pure water is among the key priority elements which need to be secured. Then one should secure sufficient amounts and high quality water supplies for the needs of the city, industry and energy, with the exception of road infrastructure. 


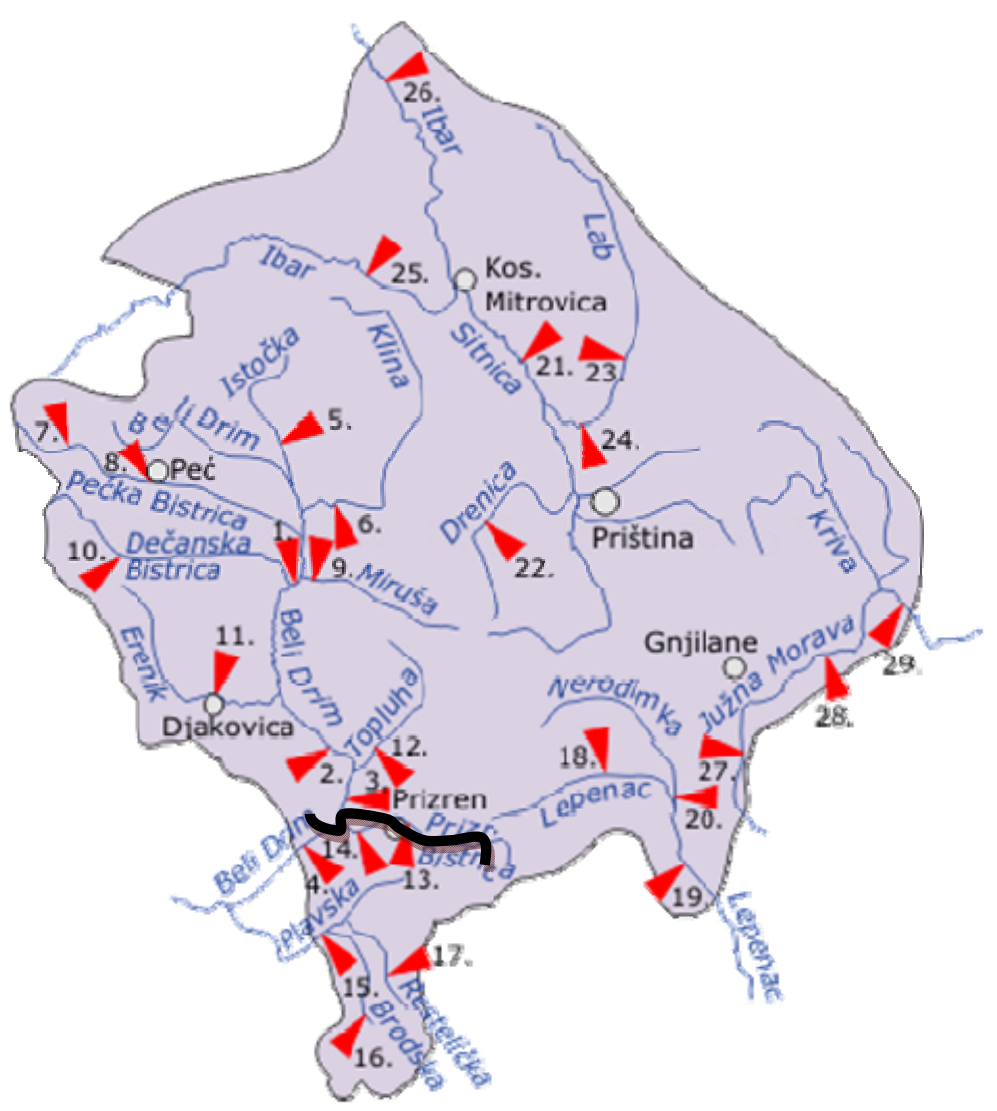

Fig. 1 Classical map, Bistrica differentiated by thickness, picture of Kosovo with the river basin.

Securing sufficient and proper quality water supplies for the needs of the city impacts health and culture life, but it is also significant in terms of opportunities to develop a country's sustainable economy. A country's studies and plans of water resources are mandatory for sustainable economic plans. Without a carefully devised hydro-economic foundation, water resources of a country cannot be either preserved or utilized [3].

Water is not an everlasting asset and these resources undergo changes during global climate changes. Countries with fluctuation in the water natural balance will not have possibilities in the region as there would be an increase in the price of water and energy expenditures for using the water and there will also be additional expenditures for water quality improvements for normal economic development.

Worldwide, around $3 \%$ of the electric energy is used to bringing waters in quotas necessary for utilization.

Various measures for the improvement of the quality of water resources are necessary.

Facilities intended for water quality improvements are of varying dimensions, depending on the processes which should be performed to improve water quality. The type and dimensions of the facilities depend on physical, chemical and bacteriological features of the water as well as on the water amounts obtained for usage. For a most rational usage, several measures should be undertaken:

- Constructing high-tech equipments;

- Reducing losses in pressure;

- Reducing losses in the flow and of measures ;

- Other efficient for water usage.

Water is the element of life (Fig. 2) in all activities to lead a normal life. The country without sufficient amounts of water cannot have state independency. Water resources are a strategic element for the 


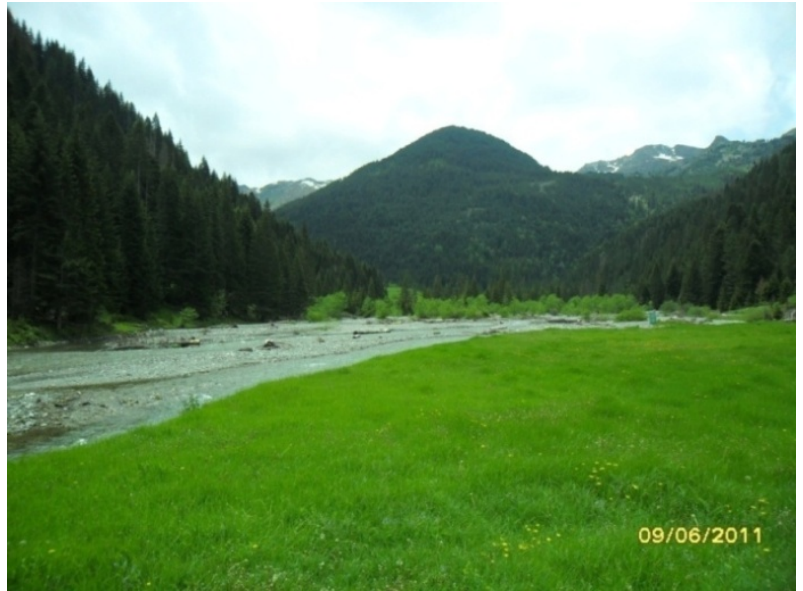

Fig. 2 Photo of the river basin on the upper part of the flow.

existence of a state, therefore the increase and purification of water resources are of great importance for a society. Development of any state in the world has been closely connected to water resources. Since the ancient times water has been the dominating element in developing settlements, economies, agricultures and other.

Many preliminary studies and analyses are required when intending to use a water resource. It is necessary to have sufficient knowledge on hydrology, meteorology, topography, geology, hydrology, logical data, etc.. Based on accurate analyses conducted on these elements, it is only by using them cautiously that these resources can be used and be protected by basin waters. Special attention should be given to the ecological flow that represents the amount of water in the river for the biological needs of flora and fauna [4].

Only when information regarding the amounts of water of a basin in certain times is collected, then the water resources of a basin can be secured for a sustainable economic development, preservation of people's health, agricultural development and protection from damages from full waters.

\section{Topography of the River}

Decani Bistrica is located in the south-western part of the Republic of Kosova. It is a part of the White Drino river basin as shown in Fig. 3.
The source of this river originated from the 'Accursed Mountains' and starts at the 2,600 quota (Kozhnieri Mountain) and flows into White Drino at the quota of 427.

The basin of this river is $P=269.90 \mathrm{~km}^{2}$ where nearly $30.02 \mathrm{~km}^{2}$ are agricultural fields and pastures $69.93 \mathrm{~km}^{2}$, forests nearly $98.70 \mathrm{~km}^{2}$ and bushes 71.60 $\mathrm{km}^{2}[5]$.

In a longitudinal aspect, this river has a highly strong current, particularly on its upper flow as it is shown in Fig. 4.

The basin has the shape of the "leaf". Rainfalls differ greatly on its upper part of the flow compared with its lower flow. Around $60 \%$ the surface of the basin is covered with various trees. The other part of the river is pasture and agricultural land. The basin has a significant descent from and rainfalls have created the numerous streams. As the climate stretching over the river basin has significant variations during the seasons, consequently there is plenty of granulated rock as shown in Fig. 5 and when full waters appear, there is also a large carriage as shown in Fig. 6 and thus the middle and lower part of the flow, there are damages of agricultural areas.

The Decani Bistrica river has a highly rapid flow. On its upper flow, it has a descent of $1>8.0 \%$; on its middle flow, it has a descent of $1.0 \%<J 2<$ $8.0 \%$; and the descent in the lower part of the flow nears at Eq. (5):

$$
J 3<1.0 \%
$$

The average steepness of Decani Bistrica river is as Eqs. (6) and (7):

$$
\begin{gathered}
S=\frac{\Delta H}{L}=\frac{(2600-427)}{52}=41.78 \mathrm{~m} / \mathrm{km} \\
\mathrm{J}_{\mathrm{av}}=4.178 \%
\end{gathered}
$$

The average steepness of the river is $4.178 \%$, but at its upper flow, the river has a greater steepness than in the lower or middle flow. Consequently, during rainfalls, one can observe a carriage of solid materials and their deposit along the banks but also on the surface of agricultural lands. 


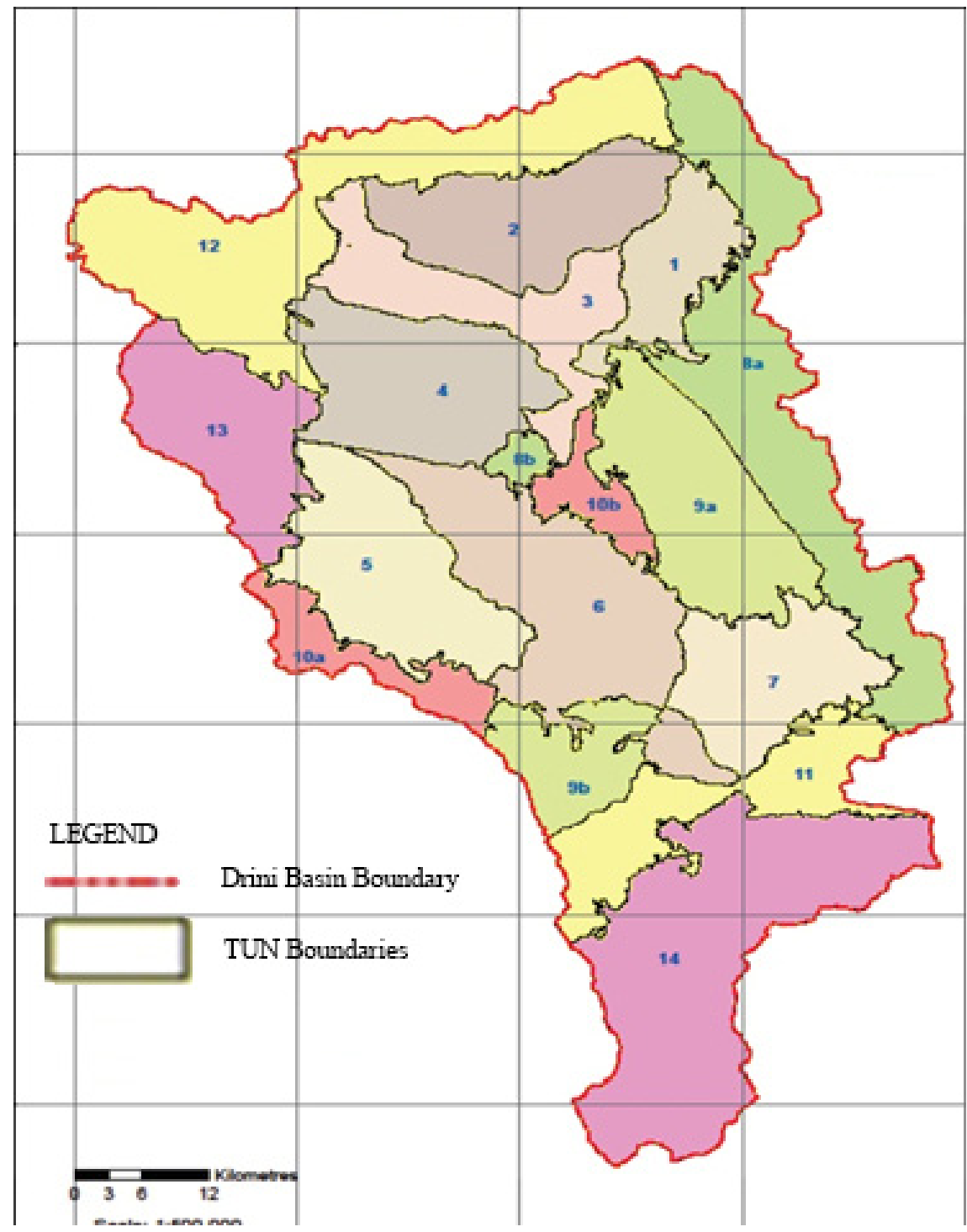

Fig. 3 Ground water bodies in the White Drino basin.

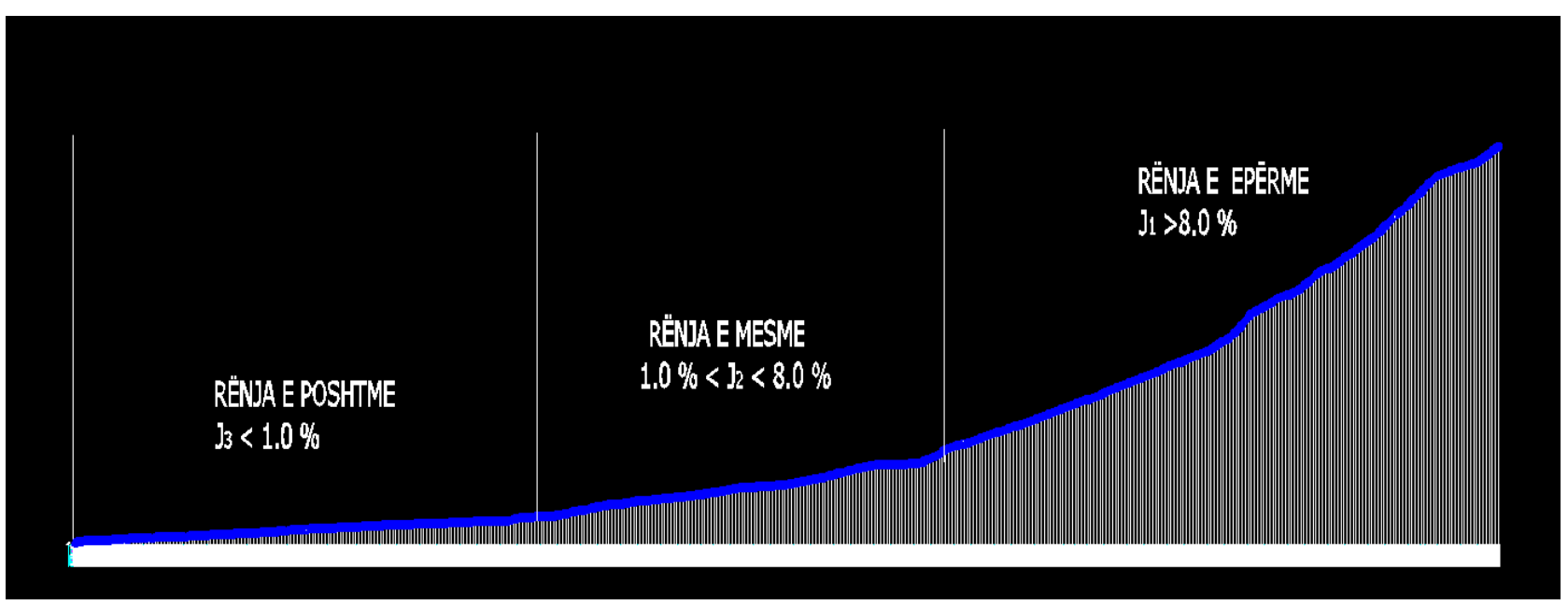

Fig. 4 The longitudinal profile of Decani Bistrica river. 


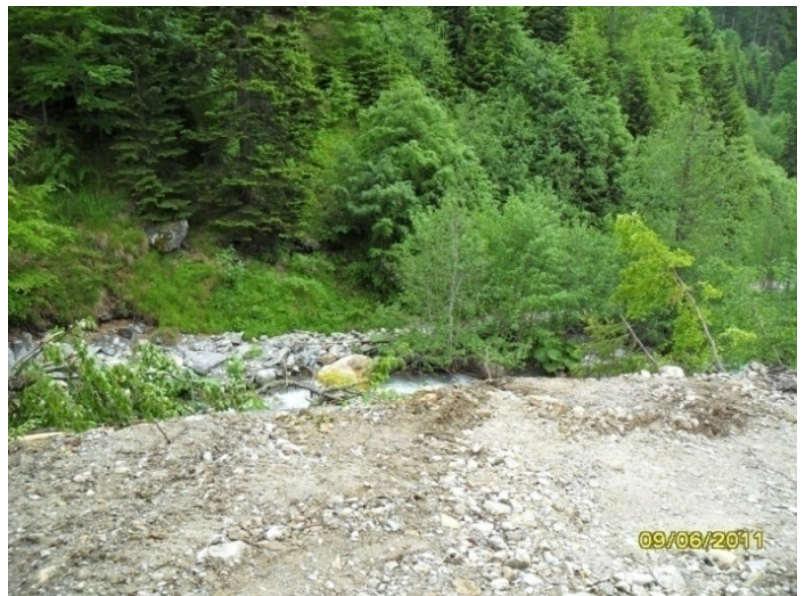

Fig. 5 Photo of the river bed during the minimal flow of the river.

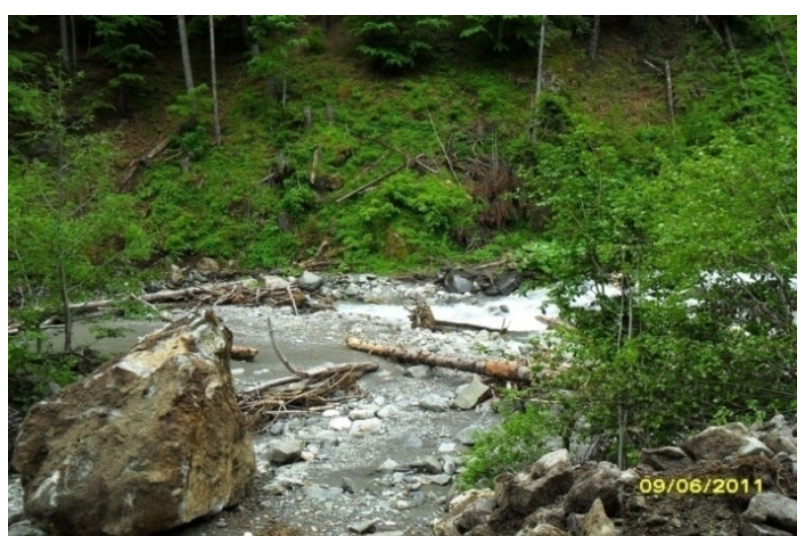

Fig. 6 Photo of the river Decani Bistrica on its minimal influx $Q_{\min }$.

\section{Hydrology}

A station for measuring the river influx is located in the river. It includes approximately $114 \mathrm{~km}^{2}$ or $42 \%$ of the total surface area; the measuring station is installed at 675.19 quota which was first installed in year 1953 .

It is mentioned that the river has only one point of recording the influx (refer to Fig. 7).

This spot is located at the 30th $\mathrm{km}$, which has approximately $42 \%$ of the water-collecting surface. There is no other profile even though authors consider the surface area of $42 \%$ to be very small in comparison to that of total surface area of the basin and other points ought to be installed in order to perform accurate influx measurements.

The water-collector of the Decani river is "leaf"-shaped which runs from the mountains of Kozhneri at the 2,253 quota and flows into White Drino at the 427 quota.

Measurements have been recorded since 1953, but there have been intermittent interruptions.

The average flow is as Eq. (8):

$$
Q_{a v}=4.72 \mathrm{~m}^{3} / \mathrm{s}
$$

Meanwhile, based on mathematical calculation, according to Gumbel's distribution, Eqs. (9)-(12) come up with:

$$
Q_{\max 50 \text { years }}=90 \mathrm{~m}^{3} / \mathrm{s}
$$

Whereas

$$
\begin{aligned}
Q_{90,100 \text { years }} & =123 \mathrm{~m}^{3} / \mathrm{s} \\
Q_{50, \% 100 \text { years }} & =163 \mathrm{~m}^{3} / \mathrm{s} \\
Q_{90 \% 100 \text { years }} & =277 \mathrm{~m}^{3} / \mathrm{s}
\end{aligned}
$$

At certain moments, the river records very high influx volume. Ground water and melted snow dominate the hydrological regime [6].

\section{Meteorology}

Meteorology stations to record rainfalls and temperatures are also installed in the region of Decani Bistrica.

This river has $F=114.6 \mathrm{~km}^{2}$ with a longitude $L=52 \mathrm{~km}$. The distance from the center of the water collector is $9 \mathrm{~km}$ and the concentration factor is as Eq. (13):

$$
K=2 F / 04=0.49
$$

and the average descent is as Eq. (14):

$$
S=\frac{\Delta H}{L}=\frac{(2600-427)}{52}=41.78 \mathrm{~m} / \mathrm{km}
$$

At the inflow of Decani Bistrica, based on measurements, the rainfall values are:

Average annual amount of rainfalls for a dry year is $870 \mathrm{~mm} / \mathrm{y}$;

Average annual amount of rainfalls for year with average humidity is $1,090 \mathrm{~mm} / \mathrm{y}$ [7];

Average annual amount of rainfalls for a humid year is $1,090 \mathrm{~mm} / \mathrm{y}$;

Average annual amount of rainfall for a humid year is $1,295 \mathrm{~mm} / \mathrm{y}$. 


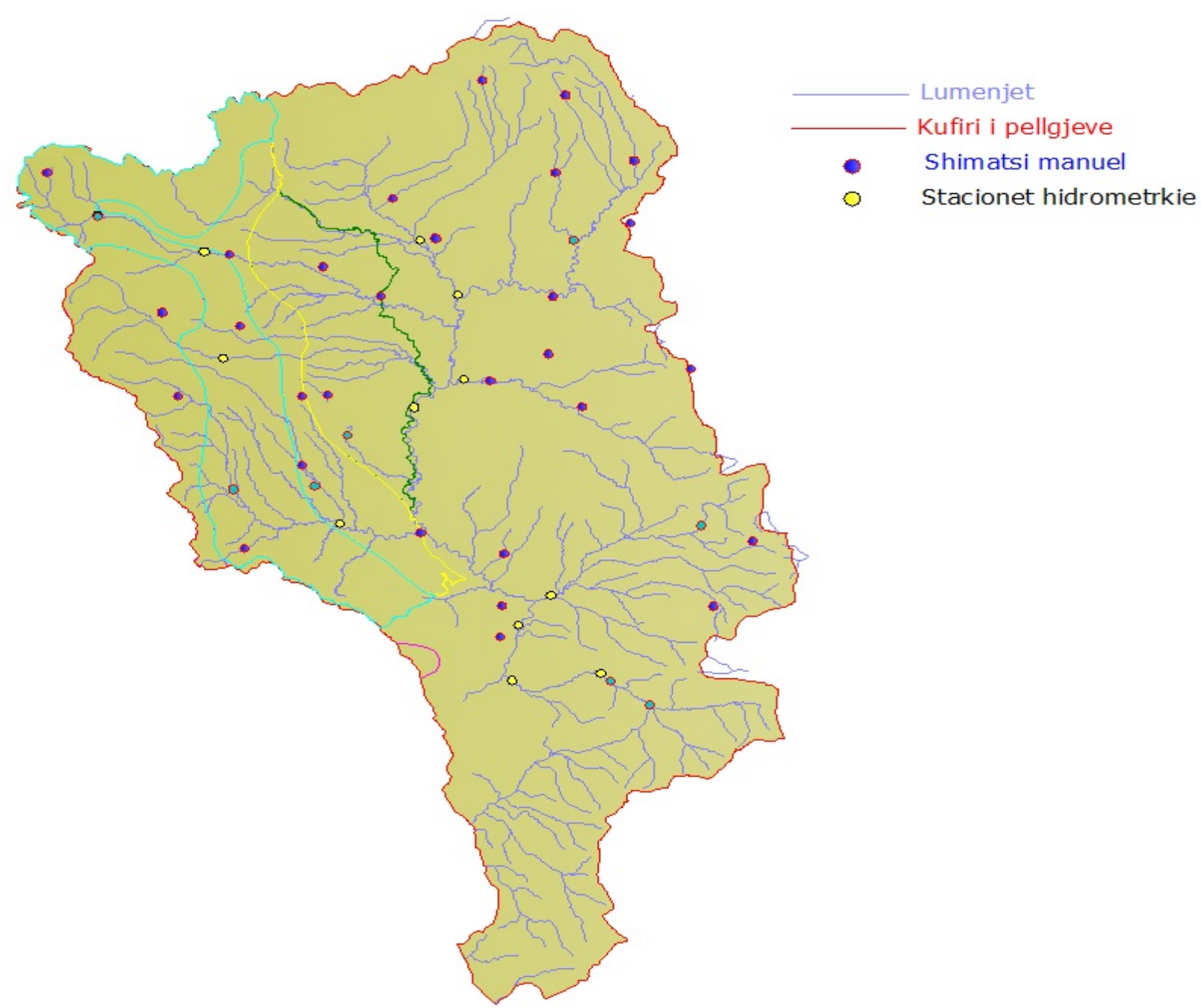

Fig. 7 Map of White Drino basin with hydrometric stations and manual rain meters [5].

Table 1 Average temperatures in Peja by season.

\begin{tabular}{llll}
\hline Winter & Spring & Summer & Autumn \\
\hline $1+1{ }^{\circ} \mathrm{C}$ & $10.9^{\circ} \mathrm{C}$ & $20.4^{\circ} \mathrm{C}$ & $12.1^{\circ} \mathrm{C}$ \\
\hline
\end{tabular}

Meanwhile, for rainfalls in the upper part of the basin are $\mathrm{H}=1,200 \mathrm{~mm} / \mathrm{y}$ in Gjakova, the nearest station. So, in year 1960, rainfall amounting at $\mathrm{H1}=$ 1,600-900 $\mathrm{mm} /$ year have been recorded—very rich in rainfalls_a humid year, whereas for a dry year $\mathrm{H}=$ 1,100 $\mathrm{mm}-700 \mathrm{~mm}$ have been recorded [8].

Average snow days in the upper part vary from $19-12$ to $25-03$.

The average temperatures in Peja by season are provided in Table 1.

In the upper parts, these values are significantly lower.

\section{Geology}

The river basin extends at a surface areas of $\mathrm{F}=$ $114.6 \mathrm{~km}^{2}$ which is covered with layers of lime rocks which destruct under the temperature's influence and then, in a form of sand, it is carried over when full waters come in [9].

Carbon rocks, lime and sedimentary rock dominate from organic remains. In the middle basin and in the lower part of the basin, there are layers of rocks and sand forms from the breakaway of lime rocks and waters carried them over when full waters came in (the melting of snow as in Fig. 8 increases the water influx). The carriage contained rocks of varying diameters over $1.0 \mathrm{~m}$ and sand of varying fractions. 


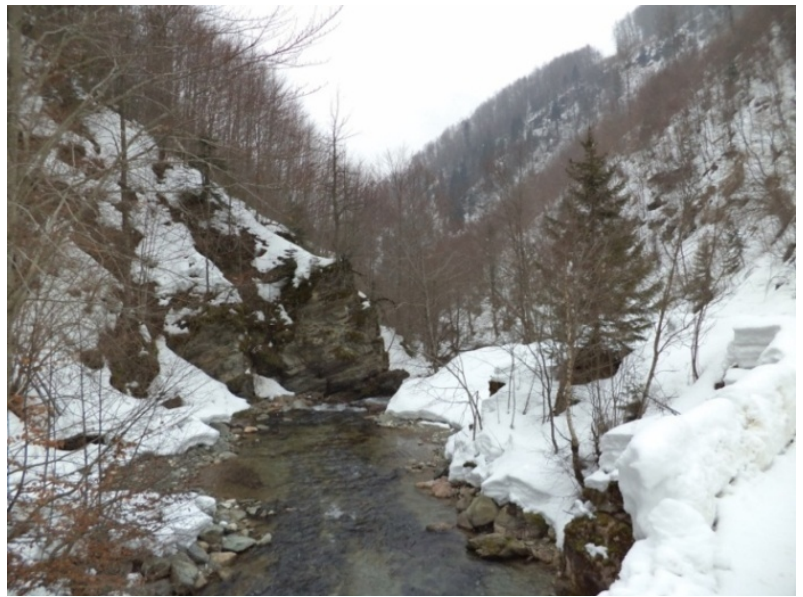

Fig. 8 Photo of snowfalls in the upper part of the river.

\section{Conclusions}

The conclusions of this study can be summarized.

This study shall present an analysis of possibilities in utilizing waters of the Decani Bistrica river basin in an optimal manner. The most recent methods will be used for the analysis of most optimal solutions in the utilizations of water resources by meeting the demands of all interested for water.

Living in the century of global crisis in the world (lack of energy and water), especially in the Republic of Kosovo, the idea is to use renewable energy sources. Among of these resources is the hydro-energy of Kosovo. Therefore, it is very important to study and use it as soon as possible.

\section{References}

[1] Institute for Hydro-economy "Jaroslav Cerni". 1983. Base of Hydro-economy of Kosovo. Beograd.

[2] IHMK (Hydro-meteorological Institute of Kosovo). 2010. Hydrological Yearbook. Prishtina.

[3] Agriculture Institute of Peja. 2004. Annual Report 2003-2004. Peja.

[4] Selenica, A. 2009. Engineering Hydrology. Tirane: Dita 2000.

[5] Energoprojekt. 1974. Water Solution of Metohija II: Hydrology Metrology. Beograd.

[6] Institute for Hydro-economy "Jaroslav Cerni". 1983. Review of Hydro Economic Base of Kosovo. Beograd.

[7] IHMK. 2014. Hydrological Yearbook 2014. Prishtina.

[8] European Community. 2004. Report on Construction and Development in Kosovo. Hydro-economics Basics of Kosovo.

[9] Energoprojekt. 1974. Water Solution of Metohija IV: Hydrogeology of Decanske Bistrice. Beograd. 